\title{
Entrevista a Nataša Petrešin-Bachelez, curadora interdependente
}

\author{
Catarina Boieiro \\ CRAL, EHESS, Paris \\ catarina.boieiro@gmail.com
}

\section{Raquel Schefer}

Universidade de Lisboa (CEC); University of the Western Cape; Universidade Nova de Lisboa (IHC). raquelschefer@gmail.com http://orcid.org/0000-0002-6353-0688

RESUMO Em junho de 2020, em pleno contexto pandémico, entrevistámos por videoconferência a curadora independente e interdependente Nataša Petrešin-Bachelez. A entrevista debruça-se sobre a atividade curatorial de Petrešin-Bachelez e as questões que a atravessam, abordando problemas como as práticas curatoriais situadas, o feminismo transnacional, os desafios de uma curadoria sustentável, a não-neutralidade do white cube e a necessidade de descolonizar as instituições museológicas.

PALAVRAS-CHAVE Curadoria; Nataša Petrešin-Bachelez; práticas curatoriais situadas; white cube; colonialidade do museu; decolonialidade.

Nataša Petrešin-Bachelez é uma curadora independente, editora e escritora eslovena que vive e trabalha em Paris. Foi responsável pela Contour Biennale 9 (Bélgica, 2019) e curadora da exposição "Musas Insubmissas: Delphine Seyrig e os Coletivos de Vídeo Feminista em França nos Anos 70 e 80", com Giovanna Zapperi (Museo Reina Sofía, Madrid; LaM, Lille). Cofundou e gere, com Élisabeth Lebovici e Patricia Falguières, o seminário "Something You Should Know", na EHESS (Escola de Altos Estudos em Ciências Sociais, Paris), desde 2006. Foi editora de L'Internationale Online (2014-2017) e da revista Manifesta (2012-2014) e codirectora do centro de arte Les Laboratoires d'Aubervilliers (2010-2012). O seu trabalho tem-se focado em temáticas como as práticas curatoriais situadas, o feminismo transnacional, a ecologia, os desafios de uma curadoria sustentável contra a lógica de crescimento permanente do sistema capitalista-colonial, a 
não-neutralidade do white cube ${ }^{1}$ e a política das slow-institutions, ${ }^{2}$ assim como a mudança das práticas laborais e o pensamento conjunto das iniciativas e dispositivos curatoriais com a equipa das instituições, desvelando a luta de classes existente no seio das próprias instituições e a transformação da infraestrutura das instituições. Partindo da premissa de que o paradigma do white cube não é inocente e de que "todas as instituições do Norte Global resultam de um processo de colonialidade do poder e de capitalismo racial" (Petrešin-Bachelez, 2018), o trabalho curatorial de Petrešin-Bachelez interroga a ligação entre as instituições museológicas e o sistema capitalista-colonial e aponta para a necessidade de descolonizar as instituições e as práticas museológicas, aspeto que consideramos fundamental no contexto político atual, marcado por reivindicações feministas e LGBTQI+, entre outras, e movimentos pela justiça social e racial como o Black Lives Matter.

A conversa com Petrešin-Bachelez decorreu em junho de 2020, por videoconferência, entre Lisboa e Paris, nova modalidade que nos impede de esquecer o contexto de pandemia - ainda numa fase de quarentena e de desaceleração imposta e generalizada, que ajuda a imaginar mudanças radicais no funcionamento do mundo da arte. Quando iniciámos a conversa, Petrešin-Bachelez começou por partilhar a sua apreensão em relação à tomada de poder pela extrema-direita na Eslovénia. Deu o tom grave para esta conversa, marcada também pela generosidade e simpatia da curadora interdependente, em que se reflete sobre as relações entre arte e política e a necessidade premente de repensar a esfera estética - e, em particular, as instituições museológicas - à luz da história europeia, dos sistemas de dominação, presentes e passados, e dos debates interseccionais em curso.

\footnotetext{
${ }^{1} \mathrm{O}$ white cube é um dispositivo museológico e expositivo de caráter ideológico introduzido no início do século XX em consonância com a crescente abstração da arte moderna e os pressupostos do modernismo ocidental. Fundado em 1929, o Museu de Arte de Moderna de Nova Iorque contribuiu decisivamente para a estandardização do white cube como paradigma expositivo da arte moderna e para a sua progressiva imposição na museologia e nos espaços de exibição. Elementos arquitetónicos e cenográficos como as paredes brancas e a iluminação homogénea procuram neutralizar e descontextualizar o espaço expositivo, enfatizando as qualidades formais das peças exibidas. Estes e outros aspetos relacionados com o white cube foram abordados em vários artigos e obras teóricas. Em 1976, Brian O’Doherty escreveu uma série de ensaios na revista ArtForum sobre a questão debruçando-se, em particular, sobre o princípio de sacralização da obra de arte inerente ao dispositivo do white cube -, publicados posteriormente no volume Inside the White Cube: The Ideology of the Gallery Space (2000). Nas últimas décadas, o dispositivo do white cube (e os seus fundamentos ideológicos) tem vindo a ser problematizado por desvincular o espaço expositivo e os objetos artísticos do contexto histórico-político e cultural em que se inserem e por veicular o princípio de autonomia da esfera estética. Procura-se, ao invés, desmontar o mito da neutralidade e da sacralidade do espaço expositivo, complexificando e diversificando os dispositivos e lugares de exibição (Petrešin-Bachelez, 2018).
}

${ }^{2}$ A propósito das slow-institutions, ver o artigo de Petrešin-Bachelez intitulado "For Slow Institutions" (2017). 


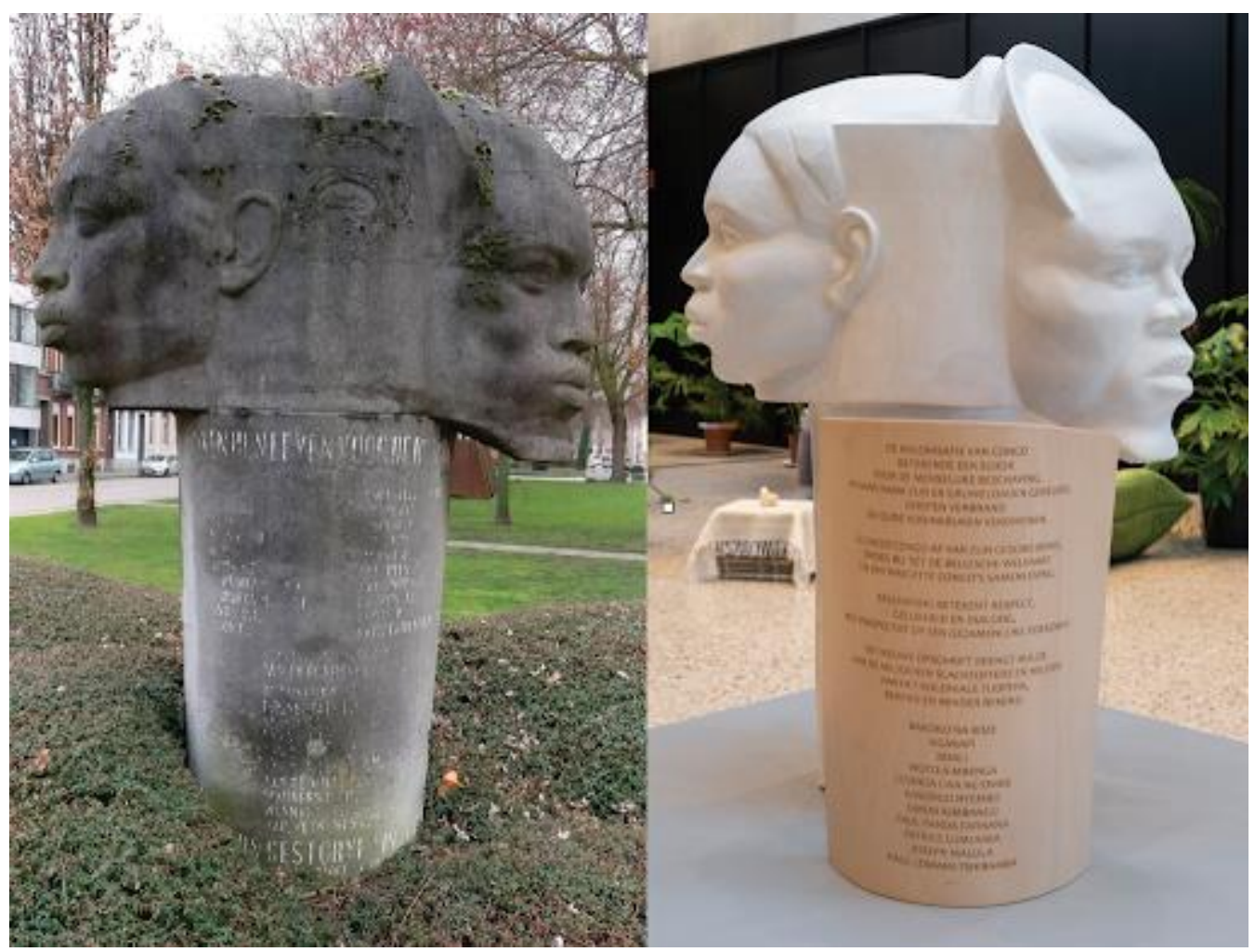

Imagem 1: Composição com a escultura original de Lode Eyckermans, em Mechelen, 1953 (à esquerda) e "The Copy", de Bie Michels, 2019, com a nova inscrição (à direita). Foto de Lavinia Wouters. (C) Contour Biennale 9.

Catarina Boieiro e Raquel Schefer - Talvez possamos começar pela curadoria da Contour Biennale, um dos projetos mais importantes que fizeste recentemente. A tua proposta para a 9aㅗำ edic̃o da bienal, sob o título "Coltan as Cotton" em Mechelen (Malinas), ${ }^{3}$ marcou uma mudança radical do formato habitual desta bienal, assim como da maioria das bienais de arte. Podes falar-nos das especificidades desta tua proposta curatorial, para uma bienal que seja organizada de forma sustentável (por oposição ao capitalismo cultural, ou seja, oposição à lógica de crescimento permanente do sistema capitalista e à mercantilização global do campo artístico)?

Nataša Petrešin-Bachelez - Desde logo, o convite foi feito num momento em que eu estava interessada nos cruzamentos entre arte e ecologia: que

${ }^{3}$ A Contour foi criada em 2003 como Bienal da Imagem em Movimento. 0 formato desta edição afastou-se do formato habitual das bienais, como um só evento pontual, e alargou-se a diferentes propostas artísticas ao longo de mais de um ano. Três fins de semana centrais orientados pelo ciclo lunar formaram a espinha dorsal do programa da bienal. Para mais informações acerca da Contour Biennale 9, pode consultar-se o site: https://www.contour9.be. 
impacto teria essa intersecção para as instituições culturais, não só em termos dos conteúdos apresentados, mas sobretudo do seu funcionamento? Então, desde que considerei aceitar o convite, já estava muito mais preocupada com essa questão de "como fazer?", do que com "o que apresentar?". Inicialmente a ideia foi acolhida com entusiasmo pela equipa, mas a sua concretização acabou por se revelar um pesadelo. Cada instituição tem os seus próprios mecanismos, as suas formas de trabalhar e sempre que alguém chega de fora, como elemento convidado, não é fácil alterar o rumo das coisas... Sobretudo quando se trata de alguém que quer analisar e repensar o funcionamento da instituição, e transformá-la através de propostas curatoriais e artísticas. Essa experiência foi uma das razões que me levaram a mudar o meu CV: de curadora independente para curadora interdependente (algum tempo depois, descobri que não era a única, por exemplo uma colega turca que vive em Amesterdão já fazia o mesmo, a Galit Eilat). Esta questão da interdependência parece-me crucial hoje em dia, quando pensamos no papel de uma curadora que não pertence necessariamente a uma instituição. É uma profissão que depende de fatores externos e enfrenta vários obstáculos, como o facto de não habitar na cidade, não conhecer todos os seus atores culturais e, mesmo quando a instituição está pronta a pôr em prática todas as ideias propostas, o facto de lidar com equipas maioritariamente brancas e um público maioritariamente branco, como neste caso. Qual é a legitimidade de trabalhar hoje nesse contexto sem querer transformar a branquitude da instituição? Foi uma experiência bastante difícil para mim, porque senti bastante hesitação e resistência da parte da instituição, por vezes falta de tato. Mais tarde, percebi que o meu papel era ser o elemento feminista killjoy, para citar Sarah Ahmed, ${ }^{4}$ que define assim o posicionamento feminista que tem de questionar e confrontar o seu contexto continuamente, onde quer que esteja. Ocupei essa posição desagradável mas necessária: partir do privilégio branco, e do meu privilégio branco pessoal, para imaginar, em primeiro lugar, como torná-lo visível e, em segundo lugar, como transformá-lo. Nessa altura surgiam na Bélgica muitos trabalhos académicos sobre o período colonial. Eu não queria inventar ideias num território onde não participo de forma quotidiana no tecido sociocultural; para mim, era importante afirmar que o papel de uma

\footnotetext{
4 Sara Ahmed é uma investigadora de teoria feminista e estudos de género, diretora inaugural do Centre for Feminist Research em Goldsmiths, Universidade de Londres e autora de vários livros. A figura da feminista "killijoy" (2017) elucida a tensão necessariamente criada pela prática de uma vida feminista quando confrontada às experiências de vida sob sistemas de patriarcado e opressão.
} 
curadora também é de reunir o que já foi feito localmente, sem ignorar as energias e atividades locais. Por exemplo, naquele momento, a atenção dirigia-se para os debates sobre a reabertura do Musée [royal d'Afrique] de Tervuren. Por isso a minha estratégia foi tomar o tempo necessário para compreender o contexto local, assumindo a necessidade de um tempo lento, por oposição à hiperprodutividade.

Outro aspeto central para a Contour Biennale 9 foi questionar a pegada carbónica da instituição. Isto traduziu-se na autoimposição de algumas restrições, tais como determinar um perímetro limitado da origem das artistas convidadas: $85 \%$ das participantes deveriam vir de comboio e foi feito um esforço ativo para procurar artistas que vivem na Bélgica e arredores, sem esquecer a questão da inclusividade social da bienal. Tenho a convicção profunda da necessidade de interseccionar ecofeminismo com um pensamento social antirracista e anticolonialista. Se fazemos uma bienal aqui e neste momento, não podemos falar de outra coisa além do que se passa aqui. Nesse sentido, investiguei o passado de Mechelen, e interessaram-me particularmente dois aspetos históricos: o aparecimento da primeira locomotiva nesta cidade (que fazia o trajeto MechelenBruxelas-Antuérpia), no início da revolução industrial, assinalando o início de uma corrida pela aceleração da produtividade prolongada até aos nossos dias. Já durante a II Guerra Mundial, durante dois anos, existiu em Mechelen um campo de concentração para pessoas judias e romenas, que eram depois enviadas para Auschwitz, onde apenas $2 \%$ sobreviveram. Acredito que é fundamental inscrever a bienal no tecido histórico da cidade, para chegar a qualquer tipo de legitimidade do programa e das propostas curatoriais.

CB e RS - E como é que essa perspetiva interseccional aliada ao pensamento do decrescimento se traduz nas práticas concretas de trabalho, nomeadamente na organização das relações de classe, género e etnia dentro da equipa e da bienal?

NPB - Quando comecei a trabalhar para a Contour, a associação que gere a bienal acabava de integrar o centro de arte Nona e já tinha relações com o movimento Welcome Refugees, bastante forte naquela altura em Mechelen. Incitei a equipa a envolver-se em mais iniciativas sociais desse género, não só enquanto cidadãos mas também enquanto instituição, como ações e gestos de hospitalidade para pessoas migrantes recém-chegadas. Também colaborámos com a associação Mophradat, de Bruxelas, que visa criar oportunidades para pessoas de origem árabe em instituições culturais e artísticas - embora, afinal, as pessoas interessadas tenham acabado por encontrar oportunidades melhores. Também tentámos estabelecer esse 
tipo de vínculos com a sociedade através de iniciativas artísticas. Por exemplo, com a artista portuguesa Maria Lúcia Cruz Correia desenvolvemos um projeto de ilha flutuante, que aborda um possível projeto utópico inserido na cidade, e cuja construção foi feita em colaboração com pessoas precarizadas que habitam a cidade (pessoas em situação de sem-abrigo ou com passados problemáticos).

Inevitavelmente, a questão do feminismo também esteve sempre no centro da minha reflexão - está sempre presente na minha vida, pois acredito que temos de "viver uma vida feminista", para citar de novo Sarah Ahmed (2017), o que quer dizer que trabalhamos nas instituições e com as instituições enquanto feministas. É impossível separar o feminismo daquilo que somos e fazemos no dia a dia. Houve momentos em que não me senti muito apoiada pela instituição e foi importante desenvolver um trabalho interpessoal entre mim e a equipa, entre a equipa e os artistas de maneira a abordar essas questões - um trabalho que também faz parte da filosofia feminista. Mas voltemos à questão sobre a maneira como a perspetiva interseccional, aliada ao princípio de uma curadoria sustentável, se reflete no trabalho coletivo e na organização hierárquica no seio da equipa da bienal. A durabilidade das iniciativas propostas varia em função da postura da instituição, se ela é mais ou menos hierárquica, ou se tenta encontrar uma coesão entre as diferentes formas de trabalho dentro da instituição. Tentei implementar práticas de commoning, que convidam a partilhar de formas diferentes as competências e recursos 5 - e como se tratava de uma pequena equipa era possível. Outro aspeto importante, mas que pode criar fricções ou debates fortes, é questionar constantemente o que faz a instituição, perguntar em conjunto: “o que é uma bienal?”. Parar regularmente para refletir se estamos a proceder de forma realmente responsável e sustentável. Por exemplo, quanto ao financiamento privado, de origens pouco éticas, tomámos a decisão coletiva de não aceitar. Afinal, não chegámos sequer a recebê-lo! Mas o que importa é que queríamos ser coerentes neste tipo de questões. Esta reflexão passa também por coisas básicas e concretas como o lixo, a reciclagem, a compostagem. Por exemplo, uma das artistas convidadas para a Contour criou um local de compostagem coletivo, no jardim em frente do centro de arte Nona (pertencente a uma academia onde artistas profissionais e amadores dão aulas a crianças e

${ }^{5}$ Commoning é um conceito e uma prática ancestral e difusa, que se refere a formas diversas de criar, cuidar, utilizar e compartilhar recursos com base na igualdade e autogestão, opondo-se à lógica mercantil capitalista. Para uma definição mais vasta, ver, por exemplo, o artigo de Valérie Fournier intitulado "Commoning: on the Social Organisation of the Commons" (2013). 
pessoas na terceira idade). A artista, Cadine Navarro, 6 intitulou esta iniciativa Black Gold, em homenagem à terra que se enriquece a si própria. O local de compostagem coletivo aí persiste até hoje. No fundo, é isso que é importante, que a instituição decida ser atentiva, decida preocupar-se e prestar atenção aos detalhes.

CB e RS - Como entrevês a vaga atual de derrubamento de estátuas e em que sentido esse processo desvela a necessidade profunda de transformar e descolonizar as instituições? Qual poderia ser o papel específico das instituições culturais e dos museus nessa transformação? E como poderíamos passar de um contexto de boas práticas das instituições culturais, como aquelas que tu própria desenvolves e concretizas, a uma transformação mais ampla, estrutural e transnacional?

NPB - Vou partir da prática artística para responder a esta pergunta ampla, mais concretamente, de três projetos que foram apresentados na Contour Biennale que falam da necessidade de uma história diferente daquela que está inscrita nos monumentos. É a diferença que Françoise Vergès (2006) faz entre "história" e "memória". A memória é diferente da história. A história dos vencedores é escrita através dos monumentos nos antigos países colonizadores europeus.

${ }^{6}$ Artista franco-americana que vive e trabalha em Paris, França. 


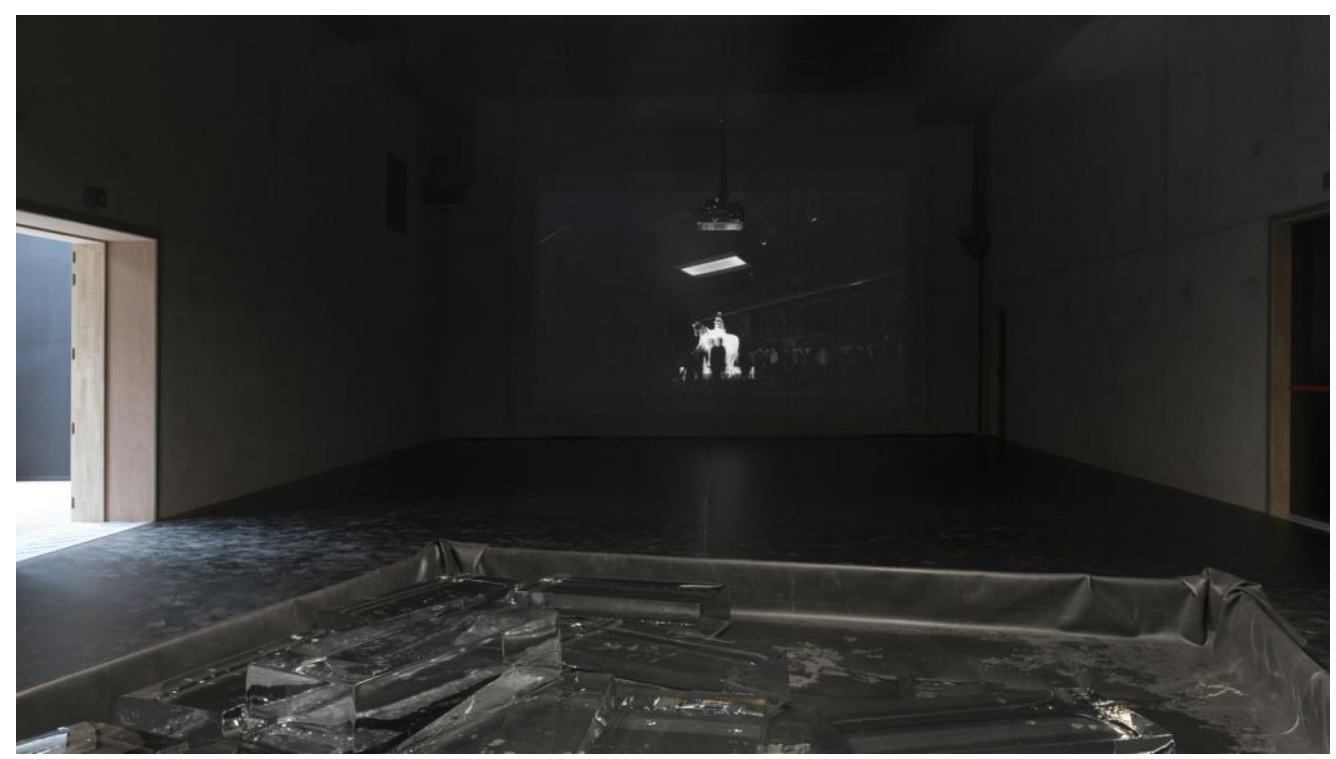

Imagem 2: PeoPL (2018), de Laura Nsengiyumva, instalação apresentada na Contour Biennale. (c) Contour Biennale 9, Lavinia Wouters.

A maior parte desses documentos fala de homens brancos; há muito poucas mulheres. Todos esses homens brancos estão ligados ao enriquecimento dos países através da colonização, tal como em França, em Portugal, na Bélgica, em Espanha, em Inglaterra, na Escócia e, um pouco menos, na Alemanha. Quanto mais avançamos para Leste, mais as estátuas são ideológicas. Na Eslovénia, por exemplo, aquando da mudança de regime, algumas estátuas, como as de Tito, foram atacadas, recontextualizadas e deslocadas, colocadas em museus. Li algures que as estátuas devem ser vistas como "dejetos nucleares", ideia que me pareceu muito pertinente. São dejetos tóxicos de um passado que importa evocar, mas não necessariamente mostrar no espaço público. Ou colocamos esse passado num envelope protetor, sabendo que continua lá, tal como acontece com os dejetos nucleares, ou, aspeto que se relaciona com a questão das instituições, levamos a cabo um trabalho reflexivo e crítico com respeito a esses monumentos. Nos museus de história contemporânea, encontramos esses monumentos, como acontece no meu país, à vista, mas narrados de outra maneira.

Durante a Contour Biennale, foram feitas três propostas para monumentos públicos. Refiro-me a monumentos escultóricos que se encontram no espaço público, já que existem outros tipos de monumentos, como os monumentos orais, efémeros, de que se fala pouco. Os monumentos públicos têm uma força singular porque testemunham um longo período de opressão. Encarnam uma memória seletiva. 0 primeiro destes três 
trabalhos foi feito pela artista flamenga Bie Michels a partir de uma escultura pública em Mechelen, uma escultura muito bela, de Lode Eyckermans, um grande escultor belga, que data de 1953 e representa dois rostos da África Central. Patrice Lumumba — sobretudo o seu perfil parece ter sido o modelo de um dos retratos. Há, contudo, uma frase inscrita na escultura: "a civilização não teria chegado ao Congo sem a intervenção dos missionários belgas". Em 2017, quando comecei a trabalhar em Mechelen, a inscrição lá estava, sem nenhuma contextualização ou comentário. Michels, que tinha nascido em Kinshasa porque o pai era professor na universidade belga, quis encarar o seu passado e a memória produzida pelo monumento. Fomos visitar o monumento algumas vezes para discutir aquilo que ele representava. Trabalhávamos também com um ativista racializado, muito implicado na questão da renomeação das ruas, que vive em Mechelen. Um dia, quando eu, Michels, o ativista e mais duas ou três pessoas racializadas conversávamos à frente do monumento, um grupo de pessoas brancas veio ter connosco dizendo "Não se toca nesse monumento! Ele pertence-nos". É preciso assinalar que Mechelen não é uma cidade muito inocente. É uma cidade da Bélgica profunda. No âmbito do projeto, Michels criou aquilo a que chamava uma commission [um comité], composta por um grupo de pessoas, quase todas de origem congolesa, que viviam em Mechelen, Bruxelas e Antuérpia, e com quem nos encontrámos várias vezes para discutir sobre uma inscrição alternativa para a escultura. 0 grupo acabou por propor uma nova inscrição, processo que foi filmado por Michels e incluído num filme. Uma petição solicitando a mudança da inscrição da escultura foi apresentada ao Presidente da Câmara de Mechelen (Bart Somers), que, por seu turno, a levou a debate no Conselho Municipal - e não ante os cidadãos. Era um Presidente da Câmara apreciado porque defendia a participação social. Contudo, houve uma enorme discrepância entre o princípio de participação social e a sua atitude frente à inscrição. 0 filme de Michels mostra o encontro entre o Presidente da Câmara e o pequeno comité, com a escultura e a sua inscrição como pano de fundo. A dada altura, o Presidente diz que a inscrição contextualiza devidamente a escultura. Um membro do comité pede-lhe, então, explicações sobre quem participou no debate que decorreu no Conselho Municipal, perguntando-lhe especificamente se nele tinham participado pessoas de origem congolesa. 0 Presidente começa a ficar irritado, a dizer que há que respeitar a democracia e pede a Michels para parar de filmar. Este episódio é muito revelador. 0 monumento conserva a inscrição até hoje, ao lado de uma pequena tabela que o Presidente da Câmara decidiu lá colocar. Este projeto artístico, que passou pela produção de uma réplica da 
escultura com a nova inscrição por Michels (The Copy, 2019, Imagem 1), mostra que o debate - e, mais precisamente, o debate coletivo - faz emergir contra-propostas.

Queria ainda fazer referência ao projeto apresentado por Laura Nsengiyumva na Nuit Blanche, em Bruxelas. A artista fez uma réplica na mesma escala do monumento de Leopoldo II em Bruxelas, monumento conhecido por ser frequentemente alvo de ataques e contestações. Nsengiyumva fez a réplica em vidro, com um grande bloco desse material, e inverteu o pedestal que serve de base à estátua. 0 pedestal foi colocado como se fosse o teto da estátua, enquanto que lâmpadas foram postas na base. 0 calor gerado pelas lâmpadas fez com que a estátua se fosse fundindo lentamente durante a noite. A artista chamou PeoPL (Imagem 2), anagrama do nome "Leopold", ao projeto e descreveu-o como um decolonial meltdown [derretimento/fusão decolonial], isto é, como um lento, ainda que importante, descongelamento das memórias de Leopoldo II. Em seguida, os restos da estátua fundida foram apresentados em forma de instalação na Contour Biennale. Nsengiyumva está atualmente muito implicada no debate sobre os monumentos. Paralelamente, fora da Contour Biennale, há associações belgas que organizam desde há muito tempo visitas decoloniais a monumentos em Mechelen, à imagem das associações francesas que fazem passeios centrados na história dos monumentos.

O terceiro projeto, da autoria de Daniela Ortiz, debruçava-se sobre a situação no Peru, onde existe uma réplica exata, ainda que em menor escala, do Palácio da Justiça de Bruxelas. No seu filme, intitulado The Empire of Law (2018, Imagem 3), Ortiz aborda a ligação entre a história da lei europeia face à história das(os) migrantes recentes na Europa e, mais particularmente, a prevalência da herança da história colonial nas leis de imigração europeias. Ortiz tem trabalhado muito sobre a reformulação dos monumentos coloniais através de diferentes propostas plásticas. A artista é a favor do apagamento dos monumentos coloniais. É importante referir a diferença entre o desmoronamento ou a destruição de um monumento por toda uma coletividade e a sua deslocação e preservação através de gestos protetores vindos do setor político. São duas ações muito diferentes em relação ao monumento. Considero que todas as instituições deveriam tomar posição frente ao papel dos monumentos na produção de conhecimento histórico. Isso acontece pouco em França de momento. É, contudo, importante referir as ações desenvolvidas por certas instituições, como o Instituto Nacional de História da Arte (INHA), nomeadamente pela historiadora e curadora Zahia Rahmani, que trabalha há muito tempo na constituição de uma bibliografia 
alternativa, favorecendo a passagem de saberes à nova geração de historiadoras e historiadores da arte. É, a meu ver, uma prática importante e que pode influenciar o debate em curso sobre os monumentos.

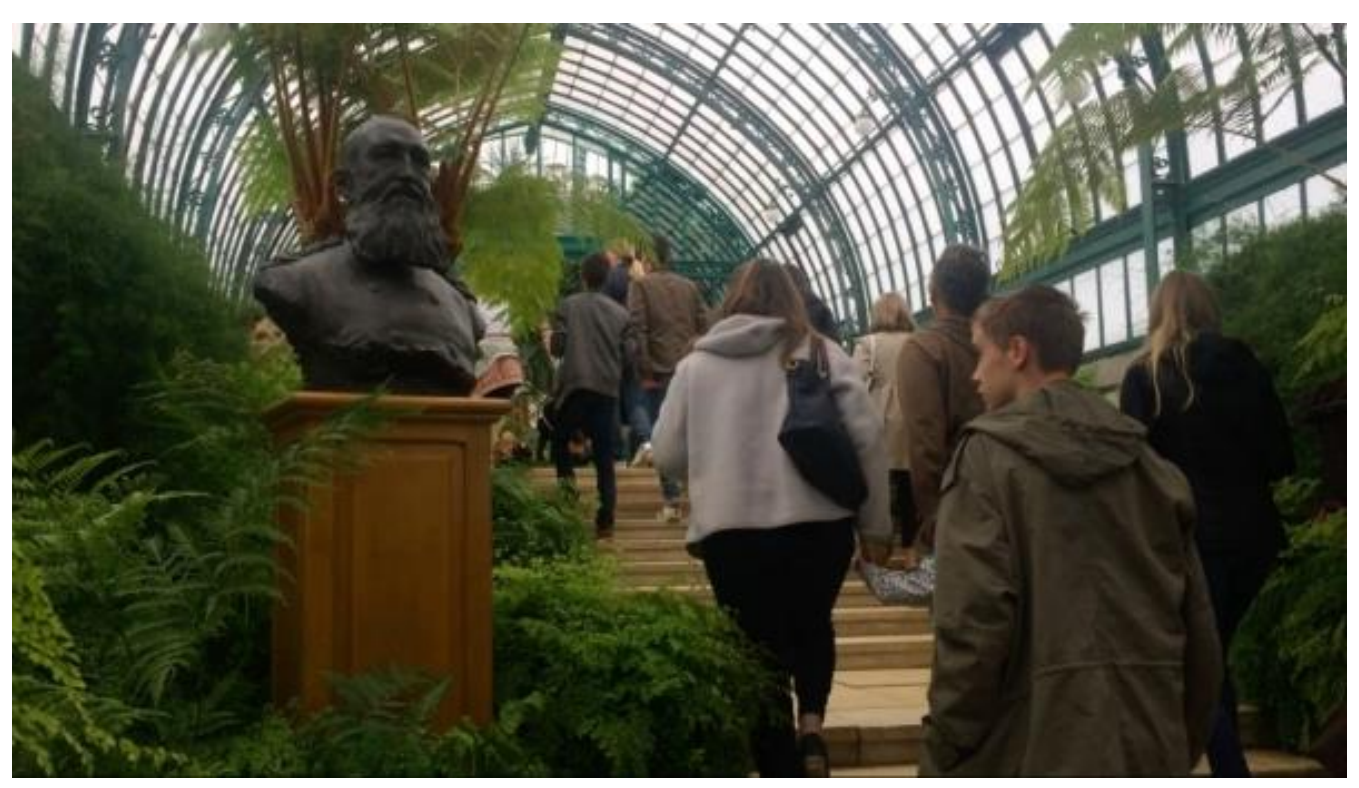

Imagem 3: The Empire of Law (2018), de Daniela Ortiz. (C) Contour Biennale 9.

CB e RS - Em que medida uma descolonização das instituições museológicas poderia favorecer, no contexto das lutas interseccionais atuais (interseccionalidade da luta contra o racismo, o machismo, o colonialismo, a persistência de formas coloniais, a colonialidade das instituições da arte, etc.), as ligações entre o museu e a sociedade, isto é, o laço entre a esfera estética e o campo social, contrariando o princípio de autonomia? Noutras palavras, em que medida poderíamos entrever uma retroatividade entre as diferentes frentes e a situação de luta e a própria descolonização museológica?

NPB - Esses processos são interdependentes. A renitência dos museus mostra que estes não são de todo interseccionais e aponta para a existência de um cânone na história da arte. Há várias escolas na história da arte. A história cultural está a ganhar terreno. Está a entrar na história da arte há décadas, com uma grande vontade de levar em conta a vida social e a história dos objetos. Está em curso uma importante discussão em torno da restituição de objetos, ao mesmo tempo que se debate a ideia de reparação dos objetos danificados ao longo da história, debate que deveria passar pelo museu, mostrando-o como uma estrutura absolutamente hierarquizante, como uma instituição cuja posição sempre tendeu a validar a existência de 
uma cisão entre a arte e a sociedade. 0 museu sempre defendeu a ideia de que a existência da arte dependia dessa rutura. Não há nenhum museu interseccional — ou há muito poucos — hoje em dia. Um possível exemplo de interseccionalidade é a rede L'Internationale, ${ }^{7}$ da qual fiz parte, e à qual estão associados por exemplo o Museo Reina Sofía, o Van Abbemuseum de Eindhoven, a Moderna galerija de Liubliana e o MACBA Museu d'Art Contemporani de Barcelona. Essas instituições têm políticas culturais um pouco mais progressistas, assim como uma vontade de falar sobre o "real" e as suas possibilidades de inscrição face à conservação e à apresentação das obras, as principais atividades dos museus. De qualquer modo, as instituições já não poderão continuar a funcionar da mesma maneira. A pressão é muito forte graças às diferentes gerações de público e às distintas posições frente às condutas museológicas. Se pensarmos na relação entre o museu e o público, encontramos, sobretudo em França, vários casos de comportamentos indesculpáveis. Penso no conceito museológico de "público", na maneira como este pressupõe um público "branco", sendo o "branco" metáfora de um público educado - ou não —, convencionalizado, bom aluno e bem-comportado nos espaços culturais públicos. Há muita coisa por fazer a este respeito. Recordo, por exemplo, o episódio que aconteceu no Museu d'Orsay há quatro ou cinco anos, quando uma turma de estudantes adolescentes entrou numa zona classificada como "prioritária" e foi expulsa do museu sob o pretexto de que tinha feito barulho. Já a exposição "0 Modelo Negro"8 visou demonstrar que o Museu d'Orsay trabalhava no sentido de uma reescrita — ou de uma nova escrita - da história da arte. Porém, pensando apenas a nível do público e nem sequer no que concerne ao nível interpessoal das equipas museológicas, penso que tudo deve ser refeito.

\section{CB e RS - Consideras que a necessária transformação da instituição museológica passa também pela mudança de atitude do público, pela adoção de uma atitude que deixe de ser passiva e contemplativa, que}

\footnotetext{
7 L'Internationale é uma confederação de sete instituições de arte moderna e contemporânea europeias caracterizada por um internacionalismo não-hierárquico e descentralizado, com base nos valores da diferença e da partilha horizontal entre uma constelação de agentes culturais, enraizados localmente e ligados globalmente. Reúne as instituições MG+MSUM (Ljubljana), Museo Reina Sofia (Madrid), MACBA (Barcelona), M HKA (Antuérpia), MSN (Varsóvia), SALT (Istambul e Ancara), Van Abbemuseum (Eindhoven) com o objetivo de partilhar recursos e promover ideias comuns.

${ }^{8}$ A exposição “Le Modèle Noir de Géricault à Matisse”, exibida no Museu d'Orsay entre março e julho de 2019 e comissionada por Cécile Debray, Stéphane Guégan, Denise Murrell e Isolde Pludermacher, procurou debruçar-se criticamente sobre o imaginário e as problemáticas estéticas, políticas, sociais e raciais ligadas à representação de modelos negras(os) nas artes visuais, concentrando-se no período compreendido entre 1794, ano da primeira abolição da escravatura em França, que seria reinstaurada em 1802 e prevaleceria até 1848, e o presente.
} 


\section{se desvincule das ideias kantianas da "arte sem finalidade" e da sensibilidade do espetador?}

NPB - De novo, considero a transformação do museu e a mudança do público como processos interdependentes. A interseccionalidade passa por essa interdependência entre os aspetos sociais e materiais constitutivos do museu. A transformação deve começar por ser feita ao nível das atividades interpessoais, isto é, das equipas museológicas. Sem que isso ocorra, como podem ser transformadas as relações com o público? Quando ocorrem transformações a esse nível, é apenas como um efeito de porosidade. Não podemos separar o que acontece ao nível das equipas museológicas e ao nível das relações do museu com o público. Há que pensar essas duas instâncias conjuntamente. A interseccionalidade no museu exige esse processo - processo difícil porque se prende com a maneira como ocupamos as posições de poder. A interseccionalidade é um método que exige que observemos e tomemos em conta a posição que nós próprios ocupamos - ou estamos numa posição de poder ou numa posição de oposição ao poder, isto é, de opressão pelo poder. Penso, contudo, que as instituições culturais deveriam estar numa zona de vanguarda, em ligação com as reivindicações que ocorrem na esfera social.

Um grupo de pessoas realizou recentemente uma ação nas instalações do Museu do quai Branly para recuperar uma estátua roubada aos seus antepassados, inspirando-se, talvez, na cena do filme Black Panther que decorre no British Museum. Ainda que literal, essa ação remete, como uma imagem-espelho, para a maneira como esse tipo de objeto museológico é percebido pelas pessoas que pertencem a culturas extraeuropeias. Falou-se muito pouco da ação depois. Soube-se que o museu chamou a polícia, mas fica-se com a impressão de que não se quer falar do assunto.

\section{CB e RS - Qual é a tua posição em relação à restituição de objetos?}

NPB - Tento acompanhar o que é dito dos dois lados. A restituição de objetos é um processo complexo que exige reflexão. Não basta colocar os objetos em caixas e enviá-los para os seus lugares de origem. Trata-se de uma questão em que, de novo, tudo está interligado. Há uma negligência por parte das instituições "ocidentais", que alegam não existirem condições de conservação nos países de origem. 0 discurso é sempre muito generalista. Contudo, a observação atenta mostra-nos que, em muitos países anteriormente colonizados e mais ou menos independentes hoje em dia, sobretudo na África Ocidental — de onde provém, fundamentalmente, o pedido de restituição —-, existem instituições, com uma longa história e um savoir-faire, que reúnem todas as condições para acolher os objetos. Porém, 
essas instituições são negligenciadas. Falta o enquadramento, o acionamento dos mecanismos necessários e, sobretudo, a vontade política. É preciso ter em conta que se tratam de objetos com uma enorme carga simbólica. Considero muito importante o parecer elaborado por Bénédicte Savoy e Felwine Sarr, parecer que ajuda a precisar a situação, a torná-la referenciável e que parte de uma vontade política. A ação no quai Branly mostra claramente que essa questão poderia ser tratada de outra forma. Se não houver resposta de parte das(os) nossas(os) políticas(os), deveríamos seguir o exemplo dessa ação. Para mim, a restituição é algo inevitável e inseparável da luta pela justiça social em relação à história. E há que notar que a responsabilidade é das instituições que aceitarem acolher os objetos restituídos. 0 mais importante é, de certa maneira, o próprio ato de restituição e, claro, a remediação e a reparação que esse ato opera. 0 debate em torno da necessidade de reunir condições nos países de origem revela condescendência e uma atitude neocolonial. Ora, é suficiente que exista vontade de acolher os objetos por parte das instituições museológicas, em coordenação com as associações e coletividades locais. A renitência ocidental está ligada à dificuldade de perder privilégios e uma posição de poder.

CB e RS - No contexto de crise provocada pela pandemia Covid-19, assistimos a uma desaceleração generalizada, incluindo das instituições culturais. Que efeitos para a arte e a curadoria? Como vês a arte após o confinamento? Fala-nos das iniciativas que desenvolveste neste contexto.

Apercebi-me rapidamente de que o verdadeiro privilégio durante o confinamento é poder ficar em casa, ter uma casa, e uma casa que não seja uma ameaça. A crise aumentou a visibilidade das enormes clivagens entre as diferentes classes sociais e privilégios, em França e não só. As ações e reflexões que eu desenvolvi focaram-se na questão do "care" [cuidado, solicitude], e na importância de reivindicar o campo artístico como pertencente ao setor do "care" e do serviço público - tal como o "public health care" [serviço público de saúde] —, não só pelo que a arte pode fazer para contribuir para que as pessoas se sintam melhor, também porque a arte pode propor reflexões e levantar questões muito importantes, mas sobretudo pelas relações que são tecidas por alguns artistas, nomeadamente como relações de cuidados interpessoais.

Foi isso que decidimos fazer com Elena Sorokina, amiga e curadora também ela interdependente. Desde logo, estabelecemos contacto com artistas com quem ela já trabalhava, requerentes de asilo ou refugiados em 
Paris, pois queríamos prestar especial atenção a estas pessoas que se encontram numa situação extremamente vulnerável. Graças à nossa proximidade com Gaëlle Choisne, que atualmente trabalha na École des Actes [Escola dos Atos] ${ }^{9}$ em Aubervilliers [nos arredores de Paris], um projeto que visa empregar jovens migrantes em espetáculos. A economia deste projeto interessante foi gravemente ameaçada pela pandemia que gerou uma crise de financiamento, já que está diretamente dependente do público. Para defender a sobrevivência do projeto, foi lançada uma campanha de crowdfunding. Paralelamente, um grupo de artistas, que vivem em Paris (maioritariamente brancas e muitas delas norteamericanas) mas bastante isoladas entre si na cidade, teve a ideia de criar linhas no espaço público que as ligassem. Então, decidimos aproximar esse dois mundos distantes, que normalmente não se cruzariam, para criar uma rede de linhas no espaço público, de modo a atrair a atenção para a escola em Aubervilliers e a sua campanha. Foi assim que surgiu o projeto No Straight Line (Forget - Me - Not) (Imagem 4). Entre os dias 7 e 10 de maio, o objetivo era traçar coletivamente uma linha entre a Place Colette, no centro de Paris, e a École des Actes, em Aubervilliers, passando por diversas ruas de Paris. Cada participante devia traçar uma linha livre, de $1 \mathrm{~km}$ no máximo - de acordo com as restrições impostas pelo confinamento em vigor naquela altura - com materiais orgânicos não poluentes, disponíveis em casa (sal, farinha, líquidos ou quaisquer pigmentos naturais). A participação, aberta a qualquer pessoa, garantia uma declaração de trabalho, autorizando a saída no contexto de confinamento - que era também um dos objetivos da iniciativa. Criou-se assim uma rede de linhas que partem de Paris e vão na direção de Aubervilliers, o que, para além de uma manifestação estética colaborativa, é sobretudo uma reflexão sobre o espaço público neste contexto peculiar em que se viu esvaziado da sua função principal de ser um espaço social. Assim como uma reflexão sobre a importância da ligação com as pessoas à nossa volta e da entreajuda entre vizinhos, que esta crise pôs a nu. Ficámos muito felizes de saber que a campanha da École des Actes recebeu bastantes doações após esta ação, partindo de uma ideia tão simples como ligar grupos diferentes. E algumas das linhas ficaram realmente muito bonitas! Houve outras iniciativa interessantes como reação ao confinamento, e inspirámo-nos em parte na

${ }^{9}$ A École des Actes é um projeto criado em 2017, em Aubervilliers, que se define como microinstituição cultural experimental e que visa reunir jovens dos bairros populares, jovens imigrantes à procura de novos lugares de vida e ainda jovens artistas e intelectuais, em torno de projetos coletivos na área das artes visuais, do espetáculo e das artes performativas. 
iniciativa de uma amiga artista, Miléna Kartowski-Aïach, que autoorganizou uma espécie de ópera entre vizinhas e vizinhos à janela, no bairro onde vive em Paris, uma iniciativa que nos impressionou pela forma como conseguiu criar novos laços, progressivamente, entre as moradoras e moradores do bairro.

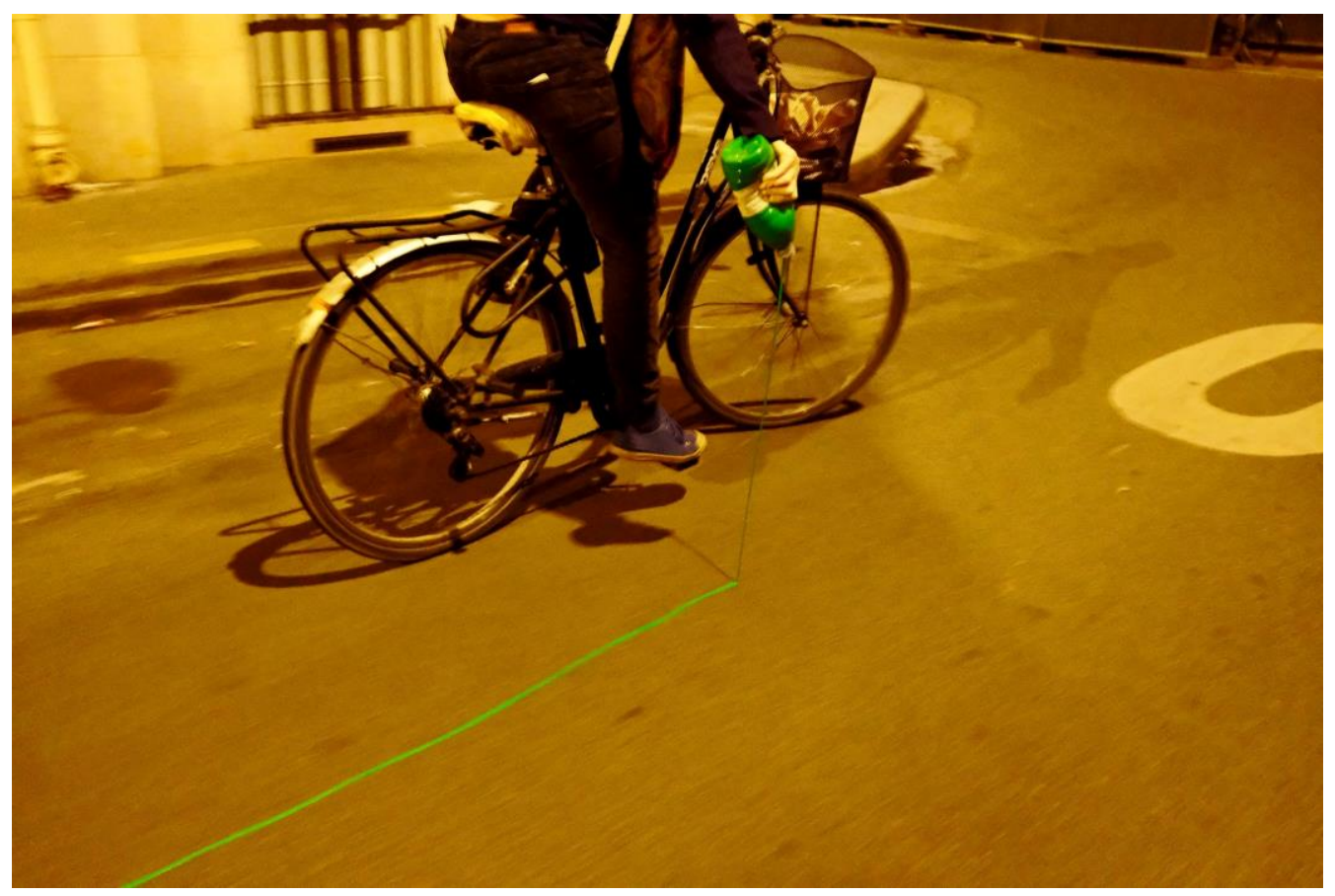

Imagem 4: Registo de uma das participações no projeto No Straight Line (Forget - Me - Not), maio de 2020. Fonte: Página de Facebook do evento NO STRAIGHT LINE or Forget-Me-Not.

Juntamente com a Elena [Sorokina], também criámos um grupo virtual de apoio entre curadores in(ter)dependentes, com reuniões quinzenais, para dialogar e pensar coletivamente acerca das mudanças e das formas como trabalhamos e nos relacionamos com as instituições; nomeadamente para convencer, de uma vez por todas, que o trabalho artístico deve ser sempre remunerado. Porque a arte, como o cuidado, é um trabalho. Ainda estamos a começar, mas não vai ser fácil.

Nesse contexto, já fomos convidadas a participar num encontro, brevemente, em Montmartre, sobre as práticas de cuidado em relação ao público de exposições, neste contexto de sanitização das instituições. Face aos novos protocolos de visita de museus e à disciplinarização do público do museu, e da sociedade no geral, o que muda na nossa experiência de receção e nos nossos hábitos de ver uma manifestação artística? Irá tornarse uma experiência semelhante a uma ida ao hospital, completamente 
assética e estéril? Como se altera a nossa perceção da obra, enquanto público, já que estamos habituados a ser corpos, uma assembleia de corpos — mas como reage o público quando é convidado a ser disciplinado?

\section{Referências}

Ahmed, Sara. 2017. Living a Feminist Life. Durham: Duke University Press.

Fournier, Valérie. 2013. "Commoning: on the Social Organisation of the Commons.” M@n@gement 16 (4): 433-453. Acesso a 6 de Janeiro de 2021: https://www.cairn.info/revue-management-2013-4-page433.htm

O’Doherty, Brian. 2000. Inside the White Cube: The Ideology of the Gallery Space. Berkeley: University of California Press.

Petrešin-Bachelez, Nataša. 2018. "Transforming Whiteness in Art Institutions." e-flux 93. Acesso a 8 de Setembro de 2020: https://www.e-flux.com/journal/93/216046/transformingwhiteness-in-art-institutions !

Petrešin-Bachelez, Nataša. 2017. "For Slow Institutions." e-flux 85. Acesso a 6 de Janeiro de 2021: https://www.eflux.com/journal/85/155520/for-slow-institutions /

Vergès, Françoise. 2006. La Mémoire enchaînée. Questions sur l'esclavage. Paris: Albin Michel.

\section{Interview with Nataša Petrešin-Bachelez, interdependent curator}

ABSTRACT In June 2020, in the middle of the COVID-19 pandemic, we interviewed the independent and interdependent curator Nataša Petrešin-Bachelez. The interview, held by videoconference, focuses on Petrešin-Bachelez's curatorial activity, addressing problems such as situated curatorial practices, transnational feminism, the challenges of a sustainable curatorship, the non-neutrality of the "white cube," and the need to decolonize museological institutions.

KEYWORDS Curatorship; Nataša Petrešin-Bachelez; situated curatorial practices; white cube; coloniality in museums; decoloniality. 